The industry's sorry state is compounded by Congress's loss of enthusiasm in the past two years. The 1980 Energy Security Act, which set up the government synfuels projects, also authorized spending on solar energy and conservation. With the dropping of all but the synfuels portion of the act, the coalition of environmentalists and oil-industry supporters that passed the act has fallen apart. A new anti-synfuels coalition, now made up of environmentalists and the much larger body of fiscal conservatives, is trying to destroy government synfuels support. So far, this coalition has had little success, but the days of government support for synfuels are surely numbered.

Stephen Budiansky

\section{High-energy physics}

\section{Labour intensive}

They have been playing musical chairs at CERN, the European Centre for Nuclear Research near Geneva. Last week there were six proposed experiments for LEP, the large electron-positron collider due to start up at the end of 1987 . Now there are four, after a preliminary examination of the proposals gave a cautious thumbs down to the other two*.

But the number of physicists remains the same, so that the 850 scientists involved in all six proposals will attempt to regroup to find jobs for all, in a process that CERN dubs "optimalization". Final approval of the arrangements will be given at a research board meeting in November.

The scale of the LEP collaborations is thus going to be vast, far bigger than foreseen only two years ago. Then, the European Committee for Future Accelerators (ECFA), in a report on the future employment of physicists in Europe, predicted collaborations averaging only 75 physicists on each of six LEP experiments. Now the figures seem likely to reach 200 on each of four experiments. Rutherford, where is you string and sealing wax now?

Dr Jack Mulvey of the University of Oxford, who produced the ECFA report, said this week that he thought the main problem was going to be project management. But particle physicists had shown a remarkable ability to adapt to new conditions. "We've realized that it takes an enormous effort to get these big experiments on the floor", he said, and that large collaborations are necessary.

The LEP collaborations will also need to be big to spread costs - for this time CERN is not following its usual policy of offering about half the capital cost of the equipment, but will restrict itself to onefifth. Since the total sum for the four experiments is some $£ 75$ million, the matter is not negligible.

The other problem is whether there will be enough jobs for the 2,000 or so particle physicists in Europe when LEP is built. Mulvey thinks there will, as the ECFA report deemed the situation satisfactory with only 450 researchers at LEP. Although the intersecting storage rings at CERN will be closed down, and there will be less work at the Super-Proton Synchrotron, there will be enough to do at the proton-antiproton collider, at the low energy antiproton ring (LEAR) and at other European laboratories such as the Deutsches Elektronen-Synchrotron in Hamburg, the ECFA report concluded.

Although "four experiments" sounds rather modest, LEP should be an excellent physics factory, provided that the particle called the neutral intermediate vector boson $\left(\mathrm{Z}^{\circ}\right)$ exists. LEP is designed to be tunable to this resonance, which is the predicted mediating particle of the electroweak interaction. If the resonance is not there, however, or if it proves difficult to tune to it, there will no doubt be 850 unhappy physicists. Robert Walgate

\section{Franco-Soviet space flight Some hitches}

The visit of "spacionaute" Jean-Loup Chrétien to the Salyut-7 space station last month has introduced an unprecedented degree of candour into the reporting of Soviet space flights. Usually, cosmonauts' post-flight press conferences gloss over technical hitches and report as "satisfactorily accomplished" even those missions that were quite obviously curtailed.

The Soviet planners clearly accepted that the presence of a Westerner would entail more candid reporting, and a few days before the launch even admitted that Salyut-7 suffered unexpected attitude changes that had had to be corrected before link-up. Attitude, however, continued to give trouble throughout the flight, both aboard the Soyuz-T transport craft and on Salyut-7 itself.

According to Chrétien, the on-board

Colonel Jean-Loup Chrétien (left) meets President Mitterrand at the Elysée Palace. computer of Soyuz-T suddenly ceased its automatic plotting just as the craft was approaching the space station at speed. This left Soyuz-T in a rolling motion, from which the crew of three had to effect a manual docking. This, Chrétien later explained on French radio, was not a breakdown - but it came at a critical moment when the crew could not even see the space station.

Orientation problems continued on board Salyut. The French contribution to the programme included high-sensitivity photography of the Earth's atmosphere and the interplanetary environment in the visible and near-infrared range. Another experiment was to photograph very weak light sources, from noctilucent clouds to distant galaxies. Both experiments required both darkness and a high degree of stability.

According to the crew commander, Vladimir Dzhanibekov, both these factors caused difficulty. The cosmonauts repeatedly lost their equipment (cameras, cassettes and so on) in the dark. Worse, flare from the thruster rockets necessary to maintain stability interfered with the lengthy exposures necessary. Dzhabenov said that such a possibility had never occurred to them before the launch.

Similar problems seem also to have arisen with the various physiological experiments. The crew is said not to have been able to think them through before launch and therefore to have had to "carry out additional training" in space. This seems remarkable - the focus of the medical programme, the French "echography" project, a Doppler measurement of blood-flow in the arteries leading to the brain, was intended to compare cadiovascular function before, during and after the flight. The crew should therefore have been familiar with the apparatus long before take-off.

The apparent lack of preparation may perhaps be due to the international nature of the flight which, contrary to Soviet practice, tied the launch to a preannounced date.

Vera Rich 